\title{
Perimplant Soft Tissue Considerations in the Esthetic Zone
}

\author{
Shivjot Chhina \\ ITS Dental College, Hospital \& Research Center, Greater Noida
}

Copyright (C) 2015 Horizon Research Publishing All rights reserved.

\begin{abstract}
One of the key elements of implant maintenance and longevity is good physiological architecture of the supporting tissues to form an appropriate environment for implants to yield both functional and cosmetic benefits. This paper analyzes the position of periimplant soft tissues which is largely determined by biological factors like periodontal bioform, the biotype, biological width and the osseous architecture which in turn determine the position of the gingival margin and the interdental papilla. The adequacy of keratinized gingiva and its relevance to implant based restorations has also been appraised. Clinical relevance: Understanding the soft tissues parameters dentists can ensure long term success and longevity of implant based restorations especially with respect to the highly demanding esthetic zone. Objective: To understand the impact of soft tissue parameters on successful outcome of implant based restorations in the esthetic zone.
\end{abstract}

Keywords Periimplant, Esthetic one, Biotypes, Bioforms

\section{Introduction}

The esthetic zone is an exacting domain as far as restoration or replacement of single or multiple teeth by implant placement is concerned. Ideal implant placement and conservation of soft and hard tissue is a decisive determinant of implant success and patient satisfaction in this zone. If implants are to succeed in answering all the needs of a partially edentulous patient, they must be forced to satisfy the same esthetic tenets as natural teeth or conventional restorations. Nowhere is this more demanding than the maxillary anterior area where the soft tissue "frame" that surrounds the prosthesis forms the centre of focus in the overall oral picture.[1]

In any implant case, the elemental frame-work of the varied and diverse components of the smile, which includethe teeth, the lips, and the gingival scaffold - must first be made to conform prior to developing the individual implant receptor sites with the identical configuration to conventional teeth; that is, an interdental papilla on each side with a rise and fall to the free gingival margin in between and the semblance of a root eminence - all in conformity with the contra lateral teeth.[2]

One of the key elements of implant maintenance and longevity is good physiological architecture of the gingiva, specifically, an abundance of keratinized tissue, and adequate thickness of tissue fibers to form an appropriate environment for implants. Good physiological architecture of the gingiva yields both functional and cosmetic benefits.

In dentate patients the margin of the gingiva describes a wavy course around the four surfaces of the teeth. With the gingival margin on the interdental surfaces constituting the most occlusally located part of the gingiva. The steepness of the arcuate form varies with the cementoenamel junction (CEJ) of different teeth.[3,4]

Periimplant mucosa like it's natural tooth counterpart is dependent on factors such as periodontal bioforms, periodontal biotype and underlying osseous topography.

\section{Periodontal Bioforms}

Periodontal bioforms are categorised into three basic gingival scallop morphologies, high, normal and flat (Fig 1). While the facial and lingual gingival scallop mimics the underlying bone architecture, which is not always the case interproximally. [5]

The norm is a discrepancy of $4 \mathrm{~mm}$ between the interproximal gingival peaks (most coronal) and the mid-facial free gingival margin peaks (most apical). When this disparity is lower than $4 \mathrm{~mm}$, a flat/oblate scallop is obvious while a greater than $4 \mathrm{~mm}$ discparity results in an exaggerated/magnified or high scallop.[6]

With a shallow scallop, the interproximal bone is thinner, and the interproximal gingival contour approximately parallel to the underlying bone contour, which in turn will expediate implant therapy since the bone has a corresponding relationship with the Free Gingival Margin(FGM) and is less amenable to post-surgical recession. With an exaggerated or high scallop, the interproximal bone is wider, but the incongruity between the 
bone contour and the FGM is problematic for amicable aesthetics (due to possible recession and creation of 'black triangles') following implant or restorative procedures.[7]
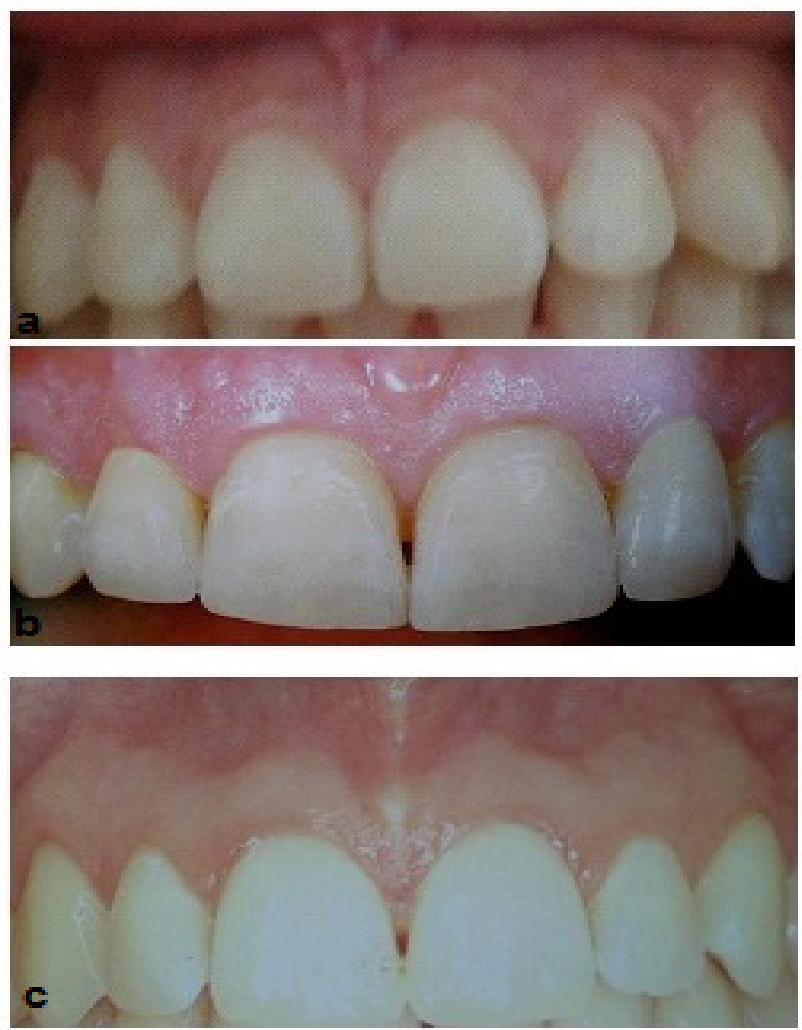

Figure 1. (a) High Periodontal Bioform (b) Flat Periodontal Bioform (c)Normal Periodontal Bioform

\section{Periodontal Biotype}

The form and the thickness of the tissue around a clinical crown can be defined as periodontal biotype. Diverse investigators have described two biotypes: the thick and the thin. The simplest way to differentiate one from the other is by means of the introduction of a periodontal probe in the sulcus (Fig 2).

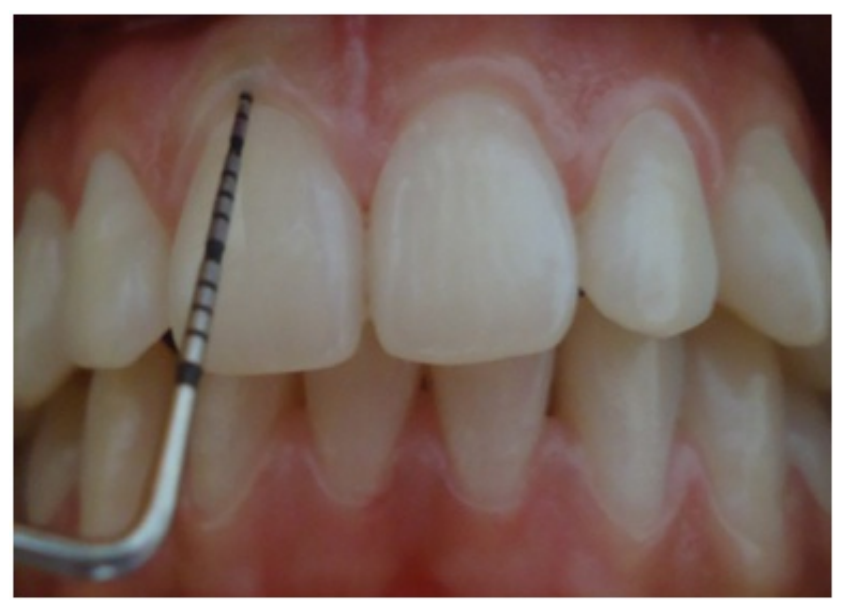

Figure 2. Biotype evaluation using periodontal probe
If the tip of the probe is visible through the gingiva, then it is a thin biotype. Both biotypes tend to respond in a different way to inflammation or to surgery.[8]

Maynard et al. [9] warned of the potential risk of soft tissue recession depending on the biotype and the remaining bone. Gingival recession is the most common complication of anterior single-tooth implants[10]. Thicker tissue is inherently more favourable whereas thinner tissue could be a cause of concern [7]. The gingival phenotype / biotype assessment can partly determine the risk for postsurgical recession. A thin, highly scalloped gingival biotype is much less resistant to trauma from surgical or restorative procedures and, consequently is more prone to recession as compared to a thick, flat gingival biotype.

Thus a thin gingival biotype would dictate a more palatal placement of the implant to decrease probability of recession and to prevent a titanium "shadow" from showing through the thin gingival tissue. Also the implant should be placed somewhat more apically to achieve a proper emergence profile and avoid a ridge lap restoration.[10]

Thicker and more fibrous gingiva allows a better esthetic result due to easier manipulation and ability to mask the metal of the implant and abutment, with a lower risk of recession. Despite the advantages associated with the thick biotype it has a predilection to scar formation subsequent to incisions or flap elevation and repositioning, which may be mandated for placing implants.

\section{Osseous Gingival Relationship}

The osseous architecture/ bone morphology in a partially edentulous individual is significantly different from a completely edentulous individual. The osseous crest rises interproximally and is lower on the buccal and lingual surfaces. The gingiva around the tooth follows this underlying bony crest very closely.[11]Becker et al [12] have classified the alveolar bone anatomic profiles into flat, scalloped, and pronounced scallop. The degree of scallop varies among the 3 types, but after extraction this profile changes, crestal bone resorbs, and soft tissue follows this contour, which is called the osseous gingival relationship[11].

\section{Interdental Papilla}

The supporting bone influences the establishment of overlying soft tissue compartments and the bone quality and quantity must be carefully assessed[13].The osseous topography resulting from tooth loss is not scalloped but flat and does not naturally support the recreation of interproximal papilla. At the interproximal sites the vertical bone height, and also the vertical height and horizontal thickness of the buccal bony wall in the edentulous site, are important elements to be considered for esthetic success[14](Fig 3). 


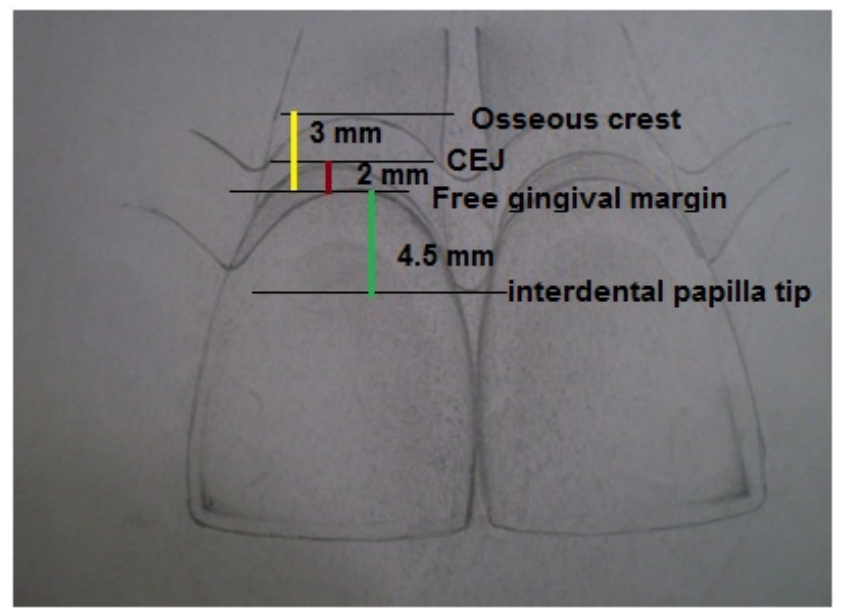

Figure 3. Diagrammatic representation of osseous -gingival relationship

The bone crest should ideally lie at a physiological distance of 2 to $3 \mathrm{~mm}$ of the cemento-enamel junction or, when recession is present, 2 to $3 \mathrm{~mm}$ of the buccal gingival margin. The distance between the underlying interproximal bone height on the adjacent natural teeth and the final prosthetic contact point dictates the formation and spontaneous regeneration of the interdental papillae associated with the implant. If this distance is greater than 5 $\mathrm{mm}$, the complete papilla formation will be compromised. This often leads to the so-called "blank triangle"15. This effect may differ according to whether the implant is adjacent to another implant or a natural tooth. Kan and colleagues reported that though the height of the interproximal papilla of the crown is independent of the proximal bone level next to the implant, despite this fact it is dependant and akin to the interproximal bone height of the neighbouring teeth.[8]

Choquet and co-workers[15] carried out a study on natural teeth adjacent to implants and concluded, that the presence of the papilla depended on the location of the alveolar crest of the neighbouring tooth, and not of the implant. If the distance was of $4.5 \mathrm{~mm}$, the papilla was formed in the $100 \%$ of the cases, while if it was of $6 \mathrm{~mm}$, the percentage was reduced halfway. This study also pointed that the minimum distance between tooth and implant should be of $1.5 \mathrm{~mm}$ to compensate for the lateral resorption after the formation of the biological width.

Tarnow et al [16] in their study demonstrated the presence of a lateral component to bone loss around implants in addition to the commonly discussed vertical component, thereby suggesting that increased crestal bone loss would result in an increase in distance between base of contact point of adjacent crowns and crest of bone. This in turn determines if papilla would be present between two implants. Selective utilization of implants with a smaller diameter at implant-abutment interface may be beneficial when multiple implants are to be placed in the esthetic zone so that a minimum of $3 \mathrm{~mm}$ of bone can be retained between them at implant-abutment level.

\section{Biologic Width}

The dimension of the physiological dentogingival junction of natural teeth is influenced by the linear dimension of the epithelial attachment and of the connective-tissue attachment along with the depth of the sulcus. This dimension is referred to as "the biological width." The mean value of the biological width around a natural tooth on an average is 2.73 $\mathrm{mm}$.[17] The implant epithelium junction though similar to the tooth-epithelium junction of the natural teeth, is relatively shorter and thinner.[18]

Due to the absence of a cementum layer around an implant, most connective-tissue fibers in the supracrestal region are oriented in a parallel direction to the implant surface.[19,20] The biological width around implants could considerably influence the nature of soft tissues and depends on myriad characteristics which include implant design, presence of adjacent teeth and the quality of soft tissue(Fig 4).

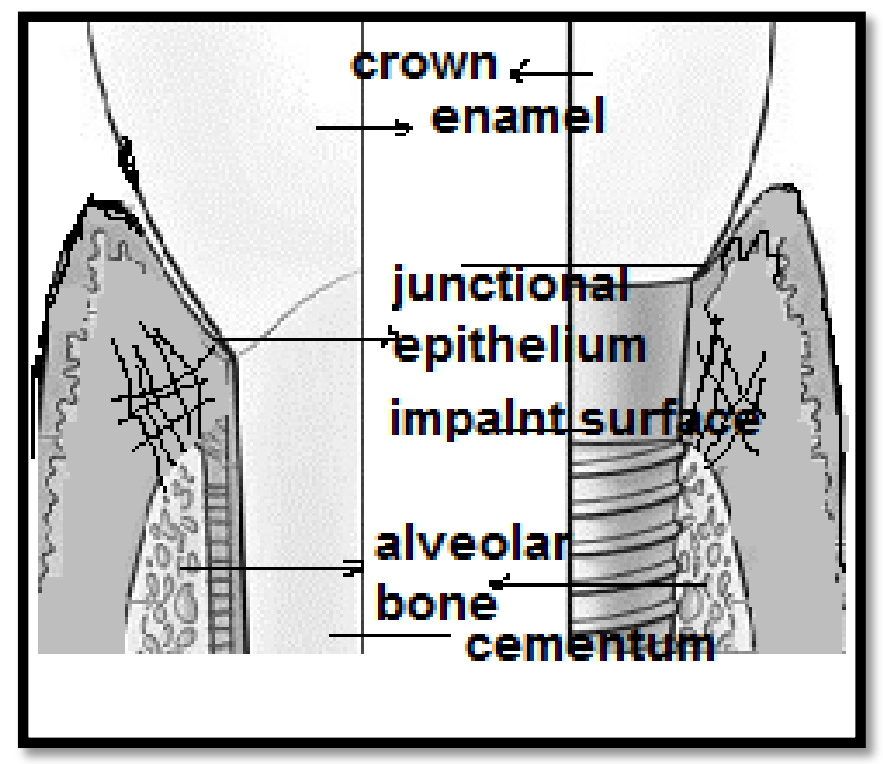

Figure 4. Diagrammatic representation of biologic width of tooth and implant

Berglundh et al. [20] studied the dimension of the periimplant mucosa in dogs and concluded that a minimum of $3 \mathrm{~mm}$ of thickness was needed to form a functional barrier and that the body always tries to re-establish this dimension. Diverse subsequent studies have observed that around the implants, once they have been exposed to the oral cavity, a bone resorption in a vertical sense from between $1.5 \mathrm{~mm}$ and $2 \mathrm{~mm}$ is produced, coinciding with the first thread of implant.

The most accepted hypothesis about the biological width is probably formed as a defensive mechanism against the bacteria that are located between the implant and the abutment and that they produce an inflammation of the surrounding tissues $[21,22]$. The deeper the implant is, the greater the vertical resorption.

The formation of the biological width is not only produced in a vertical direction, but there is a horizontal component of 
approximately $1.5 \mathrm{~mm}$ that affects the interproximal bone as well as the facial bone, which can subsequently cause retraction of the soft tissues.[16]

The biological width around a tooth and an implant present differences such as in the tooth the biological width is found supracrestal, whereas in implants it is situated subcrestal when the platform is at the level of the crest. The width is usually greater around the implant $(3 \mathrm{~mm}$ against 2 $\mathrm{mm}$ in the tooth). The histological composition also varies due to the presence of more collagen fibres that flow parallel to the periimplant surface, acting as a scar tissue, with smaller adhesion, while in the tooth the supracrestal fibres flow perpendicularly and are inserted in the radicular cementum and the alveolar bone. The periimplant tissue is also less vascularised, since it only receives contributing blood of the terminal branches of the periostium, whereas the tooth receives a dual blood supply from periosteal as well as vascular branches that come from the periodontal ligament. [23]

\section{The Keratinized Gingiva}

The keratinized gingiva is constituted by the marginal/free gingiva and the attached gingiva (Fig 5). Clinically, keratinized gingiva is a variety of masticatory mucosa that is thick and does not yield to movement when pressure is applied to the most coronal edge of the tissues.[23]

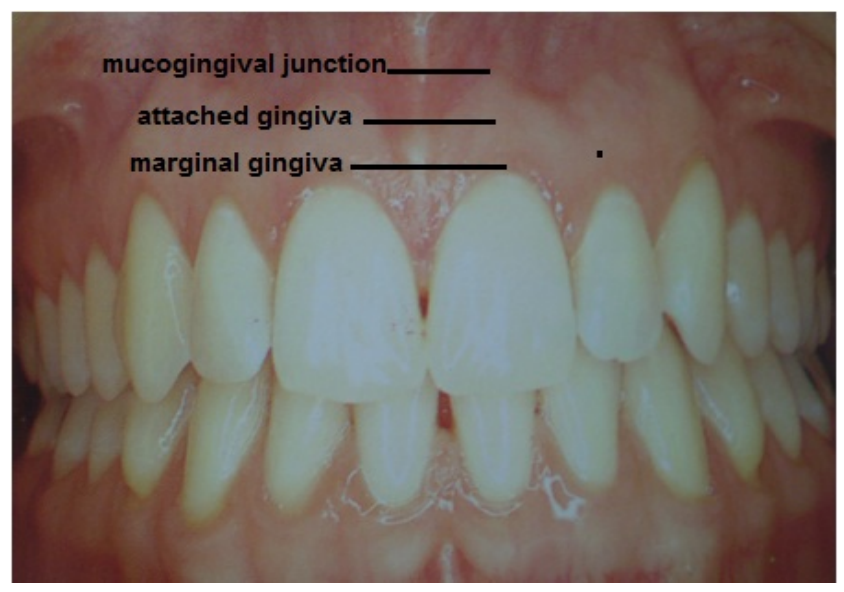

Figure 5. Keratinized gingiva

The attached gingiva extends from the marginal gingiva, and is delineated from the movable alveolar mucosa by the mucogingival junction. Histologically, attached gingiva has dense, collagenous connective tissue that is firmly bound to bone and tooth and is covered by keratinized epithelium.[25] The significance of attached or keratinized tissue around teeth has been a contentious and debatable topic for many years.[26-30] The current consensus is that keratinized gingiva, although not indispensable for tooth survival and its attachment apparatus, it does augment the long-term existence of the tooth. This is especially true if the tooth is going to be subjected to restorative stress and trauma or if it is in a dentition susceptible to periodontal breakdown, particularly recession. [31-33] Likewise the significance of keratinized tissue around dental implant has been considerably discussed. [25,34] The functional need for attached gingiva around implants though has not been confirmed but its aesthetic value has been widely acknowledged.[35]

Despite the observation that the lack of keratinized tissue does not influence implant longevity, the preservation and/or the reconstruction of keratinized mucosa around dental implants may be recommended not only to facilitate restorative procedures, but also to enhance aesthetics and plaque control [36,37].This type of tissue around an implant is vital for creation of an ideal emergence profile and an esthetic illusion of a natural tooth.[7] Thus the types of tissue that surround a dental implant codify the prerequisites for long-term health of the implant and its competence in warding off withstanding periimplantitis.[14,25]

\section{Conclusions}

Stable soft tissue and underlying osseous architecture ensure long term success and longevity of implant based restorations, more so in the esthetic zone. This paper analyzes the position of periimplant soft tissues which is largely determined by biological factors like periodontal bio form, the biotype, biological width, the osseous architecture which in turn determine the position of the gingival margin and the interdental papilla. The adequacy of keratinized gingiva and its relevance to implant based restorations has also been discussed.

\section{Conflict of Interest}

I certify that my manuscript is free of conflict of interest.

\section{Ethical Approval}

Not required.

\section{REFERENCES}

[1] Seibert J.S. Reconstruction of deformed partially edentulous ridge using full thickness onlay grafts. Part II Prosthet/Periodontal Interrelationships. Compend Contin Educ Dent .1983; 4:549-562.

[2] Garber DA, Salama M A: The aesthetic smile: diagnosis and treatment. Periodotol 2000 .1996; 11:18-28.

[3] Loe H, Listgarten M A, Terranova V P: The Gingiva. In: Genco R.J., Goldman H. and Cohen D.W. (Editors), Contemporary Periodontics. C.V. Mosby Company, St. Louis, 
MO, 1990:5.

[4] Ainamo J, Löe H. Anatomical characteristics of the gingival. A clinical and microscopic study of the free and attached gingiva. J Periodontol. 1966; 37:5-13.

[5] Ahmad I. Anterior dental aesthetics: Gingival perspective. $\mathrm{Br}$ Dent J. 2005; 199:195-202.

[6] Garguilo AW, Wentz FM, Orban B .Dimensions and relations of the dentogingival junction in humans. J Periodontol .1961; 32:261-267.

[7] Kois J C. Altering gingival levels: The restorative connection - Part 1: Biological variables. J Esthet Dent. 1994; 6: 3-9.

[8] Kan JY, Morimoto T, Rungcharassaeng K, Roe P, Smith DH. Gingival biotype assessment in the esthetic zone: visual versus direct measurement. Int J Periodontics Restorative Dent. 2010; 30(3);237-243

[9] Maynard JG Jr, Wilson RD. Physiologic dimensions of the periodontium significant to the restorative dentist. J Periodontol. 1979; 50:170-4.

[10] Spray JR, Black CG, Morris HF, Ochi S. The influence of bone thickness on facial marginal bone response: stage 1 placement through stage 2 uncovering. Ann Periodontol. 2000; 5:119-28.

[11] Khatami A H, Al-Ajmi M, Kleinman A. Preservation of the gingival architecture with the scalloped implant design: A clinical report. J Oral Implantol.2006; 32:167-170.

[12] Becker W, Ochsenbein C, Tibbetts L, et al. Alveolar bone anatomic profiles as measured from dry skulls. Clinical ramifications. J Clin Periodontol. 1997; 24:727-731.

[13] Saadoun AP, Le Gall MG. Periodontal implications in implant treatment planning for aesthetic results. Pract Periodontics Aesthet Dent. 1998; 10(5):655-64.

[14] Garber DA, Belser UC. Restoration-driven implant placement with restoration-generated site development. Compend Contin Educ Dent .1995; 16(8):796- 804.

[15] Choquet V, Hermans M, Adriaenssens P, Daelemans P, Tarnow DP, Malevez C. Clinical and radiographic evaluation of the papilla level adjacent to single-tooth dental implants. A retrospective study in the maxillary anterior region. J Periodontol. 2001; 72:1364-71.

[16] Tarnow DP, Cho SC, Wallace SS. The effect of inter-implant distance on the height of interimplant bone crest. J Periodontol .2000; 71(4):546-9.

[17] Berglundh T, Lindhe J. Dimension of the periimplant mucosa: biologic width revisited. J Clin Periodontol. 1996; 23(10):971-3.

[18] Listgarten MA, Lang NP, Schroeder A. Periodontal tissues and their counterparts around endosseous implants .Clin Oral Impl Res. 1991;2(3):1-19.

[19] Berglundh T, Lindhe J, Ericsson I, Marinello CP, Liljenberg B, Thomsen P. The soft tissue barrier at implants and teeth. Clin Oral Implants Res. 1991; 2(2):81-90.
[20] Quirynen M, Van Steenberghe D. Bacterial colonization of the internal part of two-stage implants. An in vivo study. Clin Oral Implants Res.1993; 4:158-61.

[21] Persson LG, Lekholm U, Leonhardt A, Dahlén G, Lindhe J. Bacterial colonization on internal surfaces of Brånemark system implant components.Clin Oral Implants Res. 1996;7:90-5.

[22] Abrahamsson I, Berglundh T, Glantz, P. O, Lindhe J. The mucosal attachment at different abutments. An experimental study in dogs. J Clin Periodontol .1998; 25: 721-727.

[23] Wennström JL. Mucogingival therapy. Ann Periodontol. 1996; 1:671-701.

[24] Nemcovsky CE, Ofer M. Rotated palatal flap. A surgical approach to increase keratinized tissue width in Maxillary implant uncovering: technique and clinical evaluation. Int $\mathbf{J}$ Periodontics Restorative Dent. 2002; 22:607-612.

[25] Lang NP, Loe H. The relationship between the width of keratinized gingival and gingival health. J Periodontol. 1972; 43: 623-627.

[26] Wennstrom JL. Lack of association between width of attached gingival and development of soft tissue recession. A 5-year longitudinal study. J Clin Periodontol. 1987; 14: 181-184.

[27] Salkin LM, Freedman AL, Stein MD, et al. A longitudinal study of untreated mucogingival defects. J Periodontol. 1987; 58: 164-166.

[28] Minsk L. Periodontal soft tissue grafting: the free gingival graft. Compend Contin Educ Dent. 2002; 23:850-856.

[29] Minsk L. The use of acellular dermal connective-tissue graft for root coverage in periodontal plastic surgery. Compend Contin Educ Dent. 2004; 25:170-176.

[30] De Trey E, Bernimoulin JP. Influence of free gingival grafts on the health of the marginal gingival. J Clin. Periodontol. 1980; 7:381-393.

[31] Goodacre CJ. Gingival esthetics. J Prosthet Dent. 1990; 64: $1-12$.

[32] Karlsen K. Gingival reactions to dental restorations. Acta Odontol Scand. 1970; 28:895-904.

[33] Bahat O. Interrelations of soft and hard tissues for osseointegrated implants. Compend Contin Educ Dent. 1996; 12:1161-1170.

[34] Mehta P, Lim LP. The width of the attached gingiva--much ado about nothing? J Dent. 2010; 38:517-525.

[35] Block, M. S., Kent, J. N. Factors associated with soft- and hard-tissue compromise of endosseous implants. Journal of Oral Maxillofacial Surgery.1990; 48:1153-1160.

[36] Buser, D., Weber, H. P, Lang, N. P. Tissue integration of non-submerged implants. 1year results of a prospective study with 100 ITI hollow-cylinder and hollow screw implants. Clin Oral Implants Res.1990; 1: 33-40. 